\title{
Release Behavior and Toxicity Profiles towards Leukemia (WEHI-3B) Cell Lines of 6-Mercaptopurine-PEG-Coated Magnetite Nanoparticles Delivery System
}

\author{
Dena Dorniani, ${ }^{1}$ Aminu Umar Kura, ${ }^{2}$ Samer Hasan Hussein-Al-Ali, ${ }^{3,4}$ \\ Mohd Zobir bin Hussein, ${ }^{1}$ Sharida Fakurazi, ${ }^{2}$ Abdul Halim Shaari, ${ }^{5}$ and Zalinah Ahmad ${ }^{2,6}$ \\ ${ }^{1}$ Materials Synthesis and Characterization Laboratory (MSCL), Institute of Advanced Technology (ITMA), \\ Universiti Putra Malaysia, 43400 Serdang, Selangor, Malaysia \\ ${ }^{2}$ Vaccines and Immunotherapeutics Laboratory (IBS), Universiti Putra Malaysia, 43400 Serdang, Selangor, Malaysia \\ ${ }^{3}$ Laboratory of Molecular Biomedicine, Institute of Bioscience, Universiti Putra Malaysia, 43400 Serdang, Selangor, Malaysia \\ ${ }^{4}$ Faculty of Pharmacy, Isra University, P.O. Box 22, Amman 11622, Jordan \\ ${ }^{5}$ Physics Department, Faculty of Science, Universiti Putra Malaysia, 43400 Serdang, Selangor, Malaysia \\ ${ }^{6}$ Chemical Pathology Unit, Department of Pathology, Faculty of Medicine and Health Sciences, \\ Universiti Putra Malaysia, 43400 Serdang, Selangor, Malaysia
}

Correspondence should be addressed to Mohd Zobir bin Hussein; mzobir@upm.edu.my

Received 18 February 2014; Accepted 1 April 2014; Published 8 May 2014

Academic Editor: Mehmet Yakup Arica

Copyright (C) 2014 Dena Dorniani et al. This is an open access article distributed under the Creative Commons Attribution License, which permits unrestricted use, distribution, and reproduction in any medium, provided the original work is properly cited.

\begin{abstract}
The coating of an active drug, 6-mercaptopurine, into the iron oxide nanoparticles-polyethylene glycol (FNPs-PEG) in order to form a new nanocomposite, FPEGMP-2, was accomplished using coprecipitation technique. The resulting nanosized with a narrow size distribution magnetic polymeric particles show the superparamagnetic properties with $38.6 \mathrm{emu} / \mathrm{g}$ saturation magnetization at room temperature. Fourier transform infrared spectroscopy and the thermal analysis study supported the formation of the nanocomposite and the enhancement of thermal stability in the resulting nanocomposite comparing with its counterpart in free state. The loading of 6-mercaptopurine (MP) in the FPEGMP-2 nanocomposite was estimated to be about $5.6 \%$ and the kinetic experimental data properly correlated with the pseudo-second order model. Also, the release of MP from the FPEGMP-2 nanocomposite shows the sustained release manner which is remarkably lower in phosphate buffered solution at $\mathrm{pH} 7.4 \mathrm{than} \mathrm{pH}$ 4.8 , due to different release mechanism. The maximum percentage release of MP from the nanocomposite reached about $60 \%$ and $97 \%$ within about 92 and 74 hours when exposed to $\mathrm{pH} 7.4$ and 4.8 , respectively.
\end{abstract}

\section{Introduction}

Leukemia is a type of cancer of the blood or bone marrow which can affect people at any age and the rate of cure can be depending on the age of patient as well as the types of leukemia. Leukemia can be distinguished via an abnormal proliferation and accumulation of immature white blood cells which are called blasts. The drug, 6-mercaptopurine (MP), is one of anticancer drugs that belong to the class of antimetabolites which can be used to treat different types of diseases such as inflammatory bowel disease, pediatric
non-Hodgkin's lymphoma, and leukemia [1]. Nowadays, iron oxide nanoparticles (FNPs) and their nanocomposites have found an increasing attention in biomedical application due to their unique physicochemical properties, such as surfacecoat ability, superparamagnetism, nontoxicity, high chemical stability, and high-level accumulation in the target area [2-6].

Because of strong magnetic dipole-dipole attraction between the particles in $\mathrm{Fe}_{3} \mathrm{O}_{4}$, some stabilizers such as surfactants or polymeric compounds [7] with specific functional groups have been used in order to prevent the aggregation and modify the surface of iron oxide nanoparticles [8]. 
The desirable properties of magnetic nanoparticles such as high surface area, uniform size, biocompatibility and high superparamagnetic with tailor-make properties, result in better demand of this type of nanoparticles for bioapplications $[9,10]$. It is worth noting that cationic nanoparticles, including gold and polystyrene, can cause hemolysis and blood clotting. On the other hand, generally anionic particles are quite nontoxic [11].

The drug can be either attached or loaded to the surface of superparamagnetic nanoparticles or embedded in the carrier matrix. Through the blood circulation, it can be delivered to the desired tumor site by means of an external localized magnetic field gradient [12]. Therefore, with magnetic drug targeting (MDT) system $[13,14]$ drugs can be reached and released into the target tumor site [15]. Therefore, in order to have the effective release, biodegradable and biocompatible nanoparticle formulations are desired. To increase the stability of iron oxide nanoparticles in colloidal suspension and modification of the surface, various biocompatible and biodegradable polymers such as polyethylene glycol (PEG) [16-19], polyvinylpyrrolidone (PVP) [2], polyvinyl alcohol (PVA) $[16,20,21]$, and natural polymers like chitosan [22-25] and dextran $[26,27]$ can be employed.

The surface coating of iron oxide nanoparticles with PEG chains can be used to decrease the reticuloendothelial system (RES) clearance, toxicity, and enzymatic degradation and also increase water solubility, stability of nanoparticles, and prolonged presence in the circulation half-life in vivo $[15,19]$. In addition, Food and Drug Administration (FDA) has approved the use of polyethylene glycol for human intravenous, oral, and dermal applications [15].

In the present work, we have selected 6-mercaptopurine as a model drug to be loaded into the surface of magnetite nanoparticles, precoated using polyethylene glycol (PEG) as a stabilizer and size controlling agent. The main objective of this work was to explore the potential use of iron oxide nanoparticles (FNPs) coated with PEG as a starting material for the formation of a new nanocomposite. Optimization was done by using two different concentrations of 6 mercaptopurine, $0.5 \%$ and $2 \%(\mathrm{w} / \mathrm{w})$, containing the same amounts of PEG. The effect on viability of leukemia cell lines (WEHI-3) when exposed to these compounds (FPEGMP0.5 and FPEGMP-2) was examined. The resulting optimized nanocomposite (FPEGMP-2) was then used as a controlledrelease formulation of active drug, MP.

\section{Materials and Methods}

2.1. Materials. Analytical grade chemicals were used in this work without further purification. Chemicals used for the synthesis of iron oxide nanoparticles were ferrous chloride tetrahydrate $\left(\mathrm{FeCl}_{2} \cdot 4 \mathrm{H}_{2} \mathrm{O} \geq 99 \%\right.$, Merck KGaA, Darmstadt, Germany), ferric chloride hexahydrate ( $\mathrm{FeCl}_{3} \cdot 6 \mathrm{H}_{2} \mathrm{O}$, 99\%, Merck, KGaA, Darmstadt, Germany), and ammonia solution (25\%) from Scharlau. For coating of iron oxide with polymer, polyethylene glycol with average M.W. 300 was used, purchased as a raw material from Acros Organics BVBA. 6-Mercaptopurine monohydrate with $99.5 \%$ purity was purchased from Acros Organics (Fair Lawn, NJ, USA). Dimethyl sulfoxide (DMSO) was supplied by Ajax Finechem (Sydney, Australia) and distilled deionized water $\left(18.2 \mathrm{M} \cdot \Omega \mathrm{cm}^{-1}\right)$ was used throughout the experiments.

2.2. Preparation of Magnetite Nanoparticles. To synthesize iron oxide nanoparticles, a mixture of $2.43 \mathrm{~g}$ ferrous chloride tetrahydrate, $0.99 \mathrm{~g}$ ferric chloride hexahydrate, and $80 \mathrm{~mL}$ of distilled deionized water in the presence of $6 \mathrm{~mL}$ of ammonia hydroxide ( $25 \%$ by mass) was exposed to ultrasonic irradiation for around 1 hour as previously reported by Lee and coworkers [28]. Then the precipitates were centrifuged and washed for 3 times to remove all impurities, washed and dispersed into $100 \mathrm{~mL}$ distilled deionized water, and mixed by $2 \%$ PEG. The mixture was stirred for 24 hours and the resulting black precipitates were collected by a permanent magnet, washed for 3 times to remove the excess polymer (PEG) which is not participated in the coating process, and then dried in an oven. The $2 \%$ of drug solution, 6mercaptopurine, which was dissolved in dimethyl sulfoxide, was added to the magnetite-PEG and the mixture was stirred for $24 \mathrm{~h}$. Finally, the coated magnetite was washed for three times and dried in an oven. In addition, to optimize the percentage of drug loading, two different percentages $(0.5 \%$ and $2 \%$ ) were prepared using the same amount of PEG (2\%) under the same conditions. We compared the two nanocomposites (FPEGMP-0.5 and FPEGMP-2) in terms of their cytotoxic effect on antileukemic cancer cell lines.

\section{Cell Viability Study}

3.1. Cell Culture. A mouse myelomonocytic leukemic cell line, WEHI-3B, was obtained from American Type Culture Collection (Manassas, VA, USA). The cells were cultured in DMEM medium (Dulbecco's Modified Eagle Medium, Gibco) supplemented with $10 \%$ heat inactivated foetal bovine serum (FBS) and $1 \%$ antibiotics (100 units $/ \mathrm{mL}$ penicillin $/ 100 \mathrm{mg} / \mathrm{mL}$ streptomycin). Cells were grown in a humidified incubator at $37^{\circ} \mathrm{C}\left(95 \%\right.$ room air, 5\% $\left.\mathrm{CO}_{2}\right)$ and used for seeding and treatment after reaching $90 \%$ confluence. The media were changed after two days and subculture was done between 3 and 5 days throughout the experiment.

Cells were seeded at $1 \times 10^{5}$ cells $/ \mathrm{mL}$ into 96 well plates and left overnight in a $\mathrm{CO}_{2}$ incubator to get attached. The coated or uncoated nanoparticles, pure 6-mercaptopurine, were dispersed in DMEM medium and $100 \mu \mathrm{L}$ final volume per concentration was added to each well. A stock solution of $10 \mathrm{mg} / \mathrm{mL}$ from each nanoparticles and pure 6mercaptopurine was prepared in media and subsequently diluted to obtain the desired concentration of 1.87-60 $\mu \mathrm{g} / \mathrm{mL}$. Wells containing cells and media only were used as control.

3.2. Cytotoxicity Testing. The cytotoxicity and anticancer effects of the drugs on the cells were measured using MTT (SIGMA) proliferation assay. In brief $20 \mu \mathrm{L}$ of MTT solution ( $5 \mathrm{mg} / \mathrm{mL}$ in phosphate buffered saline) was added to each well and left in the incubator at $37^{\circ} \mathrm{C}$ for 2 hours. The medium 
containing MTT was removed gently and replaced with dimethyl sulfoxide (DMSO) $100 \mu \mathrm{L} /$ well. This is to dissolve the blue crystals formed due to the reduction of tetrazolium by living cells. Absorbance at $570 \mathrm{~nm}$ and $630 \mathrm{~nm}$ (background) was measured using a microplate enzyme-linked immunosorbent assay reader (ELx800, BioTek Instruments, Winooski, VT, USA). All experiments were carried out in triplicate and the results are presented as the mean \pm standard deviation:

$$
\text { Cell viability }(\%)=\frac{[\text { Average }] \text { test }}{[\text { Average }] \text { control }} \times 100 \text {. }
$$

3.3. Controlled-Release Study. In order to study the drug release profiles of 6-mercaptopurine (MP) from FPEGMP2 nanocomposite, two $\mathrm{pH}$ levels (7.4 and 4.8) were used at $25^{\circ} \mathrm{C}$ due to the similarity to the $\mathrm{pH}$ of blood and that of stomach, respectively $[1,18,29-31]$. About $10 \mathrm{mg}$ of FPEGMP2 nanocomposites was added to the mixture of $1 \mathrm{~mL} \mathrm{HCL}$ and $3 \mathrm{~mL} \mathrm{HNO}_{3}$ and marked it up to $25 \mathrm{~mL}$ by distilled deionized water and stirred for around $1 \mathrm{~h}$. Due to the observed intense absorbance at $330 \mathrm{~nm}$ in the UV-Vis spectrum, the accumulated release amount of MP from FPEGMP2 nanocomposite was measured at $\lambda_{\max }=330 \mathrm{~nm}$. It is obvious that phosphate buffered solution contains different anions such as $\mathrm{Cl}^{-}, \mathrm{HPO}_{4}{ }^{2-}$, and $\mathrm{H}_{2} \mathrm{PO}_{4}{ }^{-}$, which can affect the rate of the release.

\section{Characterization}

Powder X-ray diffraction patterns were obtained in a range of 5-70 using a Shimadzu diffractometer, XRD-6000 (Tokyo, Japan), instrument to determine the crystal structure of the samples using $\mathrm{CuK}_{\alpha}$ radiation $(\lambda=1.5406 \AA)$ at $40 \mathrm{kV}$ and $30 \mathrm{~mA}$. Fourier transform infrared spectra of the materials were recorded over the range of $400-4000 \mathrm{~cm}^{-1}$ on a Thermo Nicolet FTIR (AEM, Madison, WI, USA) with $4 \mathrm{~cm}^{-1}$ resolution, using the $\mathrm{KBr}$ disc method with approximately $1 \%$ of the sample in $200 \mathrm{mg}$ of spectroscopic grade potassium bromide, and the pellets were pressed at 10 tons. Thermogravimetric and differential thermogravimetric analyses (TGA-DTG) were performed using a Mettler-Toledo instrument (Greifensee, Switzerland) in $150 \mu \mathrm{L}$ alumina crucibles in the range of $20-1000^{\circ} \mathrm{C}$ at a heating rate of $10^{\circ} \mathrm{C} / \mathrm{min}$. In order to observe the morphology, average particle size, and size distribution of iron oxide and FPEGMP-2 nanocomposite, transmission electron microscopy (Hitachi, H-7100 at an accelerating voltage of $100 \mathrm{kV}$ ) was used. An ultravioletvisible spectrophotometer (Shimadzu 1650 series, Tokyo, Japan) was used to determine the optical and controlledrelease properties of MP from the FPEGMP-2 nanocomposite.

\section{Results and Discussion}

5.1. Powder X-Ray Diffraction. The X-ray diffraction patterns of the naked magnetite iron oxide nanoparticles (FNPs) and iron oxide nanoparticles coated with polyethylene glycol and 6-mercaptopurine (FPEGMP-2) are shown in Figure 1.

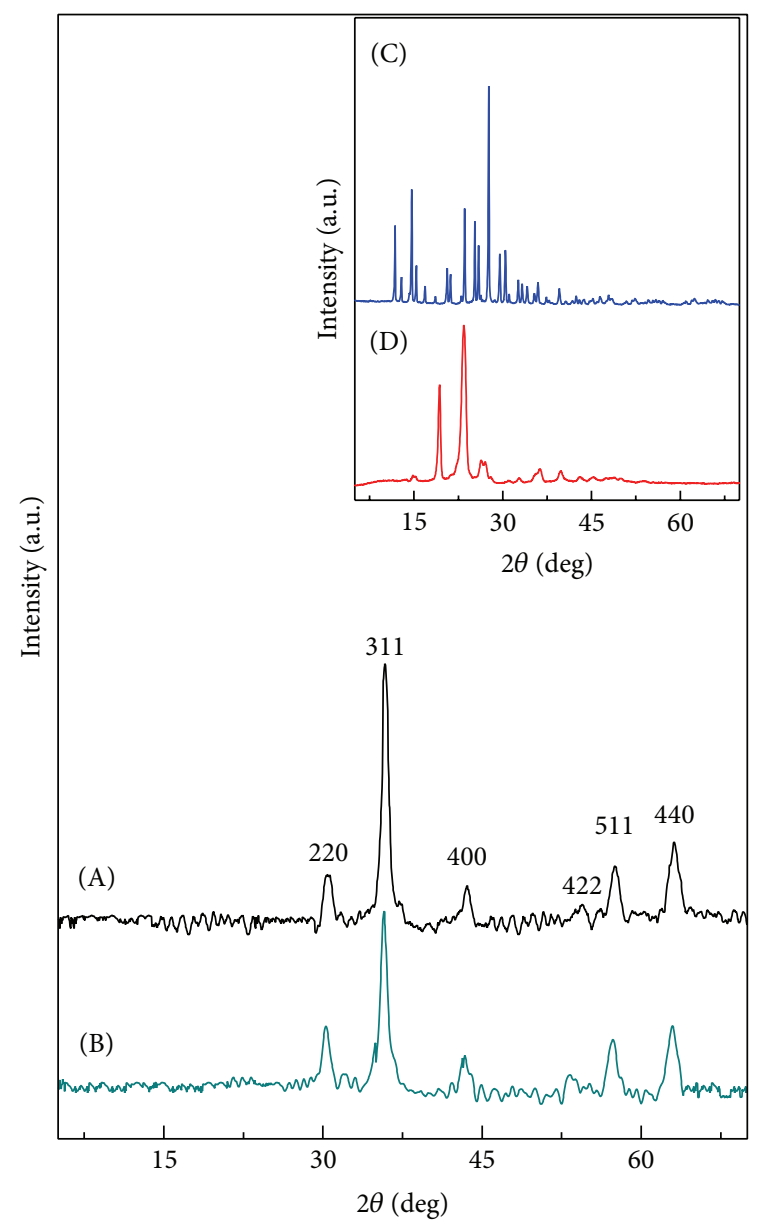

FIGURE 1: XRD patterns of FNPs (A) and FPEGMP-2 nanocomposite (B). The inset shows the XRD patterns of pure MP (C) and pure PEG (D).

The inset of Figure 1 shows the XRD patterns of pure 6mercaptopurine (MP) and the polyethylene glycol (PEG). The two main diffraction peaks revealed at $2 \theta=10.5^{\circ}$ and $20.6^{\circ}$ in Figure $1(\mathrm{C})$ were the characteristic diffraction peaks of pure PEG [32]. The diffraction pattern of pure MP shows many intense sharp peaks in the fingerprint region, indicating the crystalline nature of MP that can be observed at $2 \theta=11.8^{\circ}$, $14.6^{\circ}, 16.8^{\circ}, 21.2^{\circ}, 23.5^{\circ}, 25.3^{\circ}, 25.9^{\circ}, 27.5^{\circ}, 29.5^{\circ}$, and $30.3^{\circ}$ (Figure 1(D)) [1].

Six characteristic peaks can be observed in FNPs and FPEGMP-2 nanocomposite which were marked by their indices (220), (311), (400), (422), (511), and (440) Bragg reflection, appeared at $2 \theta=30.1,35.9,43.3,54.2,57.8$, and 63.2, respectively. These peaks confirm that the resultant FNPs was pure magnetite $\mathrm{Fe}_{3} \mathrm{O}_{4}$ with a cubic inverse spinal structure $[33,34]$. Due to the absence of the characteristic superlattice diffractions at (210), (213), and (300), it can be confirmed that there is no coexistence of maghemite $\left(\gamma-\mathrm{Fe}_{2} \mathrm{O}_{3}\right)$ phase in both iron oxide nanoparticles and FPEGMP-2 nanocomposite [35, 36]. Moreover, the result shows that the coating process and the modification of iron oxide nanoparticles after coating with polymer and drug (PEG-MP) did not result in any 


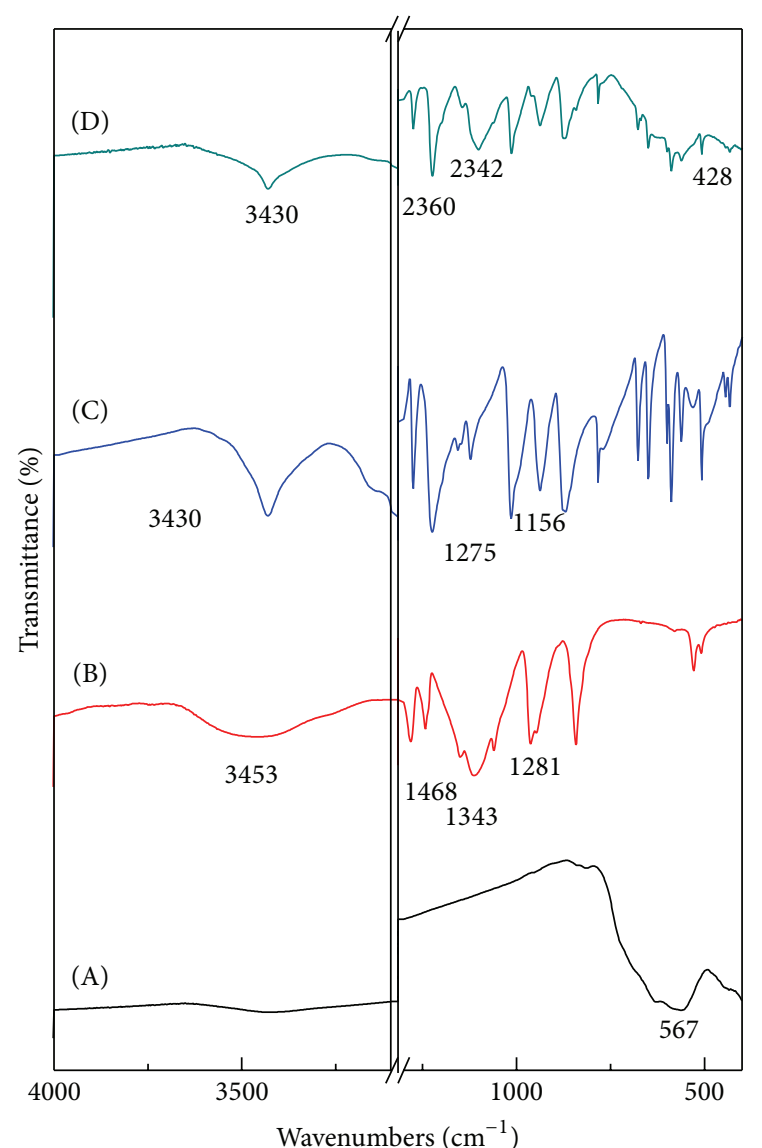

Figure 2: FTIR spectra of FNPs (A), pure PEG (B), pure MP (C), and FPEGMP-2 nanocomposite (D).

phase change of the crystal structure of magnetite iron oxide nanoparticles $[3,15,37]$. Using the Debye-Sherrer equation $(D=K \lambda / \beta \cos \theta)$, the average crystallite size of the FNPs was calculated using the (311) XRD pattern, resulting in a value of about $3 \mathrm{~nm}$ [33].

5.2. Infrared Spectroscopy (FTIR). In order to realize the attachment of polymer (PEG) to the magnetite nanoparticles and the mechanism of binding, infrared spectroscopic technique was used. Fourier transform infrared (FTIR) spectra for the iron oxide nanoparticles (FNPs), pure polyethylene glycol (PEG), pure 6-mercaptopurine (MP), and iron oxide nanoparticles coated with PEG and MP (FPEGMP-2) are shown in Figure 2. In case of naked iron oxide nanoparticles, a band observed at $567 \mathrm{~cm}^{-1}$ is assigned to stretching vibration of $\mathrm{Fe}-\mathrm{O}$ in $\mathrm{Fe}_{3} \mathrm{O}_{4}$ which is shifted to lower wavenumber, $428 \mathrm{~cm}^{-1}$, due to the $\nu_{\mathrm{Fe}-\mathrm{S}}$ and $\nu_{\mathrm{Fe}-\mathrm{N}}$ vibration modes (Figure 2(A) and (D)) [1, 22]. In Figure 2(B), the main characteristic absorption bands appearing at $2889 \mathrm{~cm}^{-1}$ can be assigned to $\mathrm{C}-\mathrm{H}$ stretching vibration and another two bands at $1468 \mathrm{~cm}^{-1}$ and $1343 \mathrm{~cm}^{-1}$ belong to the $\mathrm{C}-\mathrm{H}$ bending vibration. In addition, two characteristic bands at $1281 \mathrm{~cm}^{-1}$ and $1094 \mathrm{~cm}^{-1}$ can be assigned to the $\mathrm{O}-\mathrm{H}$ and $\mathrm{C}-\mathrm{O}-\mathrm{H}$ stretching vibration, respectively [38].
The absence of a band at $1156 \mathrm{~cm}^{-1}$ which belongs to the $\left(v_{\mathrm{C}=\mathrm{S}} /\right.$ ring vibration $)$ confirms the participation of an exocyclic (S) atom in metallic bonding of the heterocyclic ligand in the $\mathrm{Fe}(\mathrm{II})$ coordination compound (Figure 2(D)) [39]. In addition, the absence of the characteristic absorption band at $1275 \mathrm{~cm}^{-1}$ ( $\mathrm{C}=\mathrm{S}$ group) in the FPEGMP-2 nanocomposite, compared to pure 6-mercaptopurine, confirmed the formation of the 6-mercaptopurine complex by the sulfur atom (Figure 2(D)) [39]. An absorption band at $428 \mathrm{~cm}^{-1}$ in the FPEGMP-2 nanocomposite proved the presence of magnetite nanoparticles after coating procedure. Therefore, this clearly indicates that the iron oxide nanoparticles were successfully coated with PEG and MP.

5.3. Thermal Analysis. In order to study the physical changes in the materials, thermogravimetric and differential thermogravimetric analyses (TGA-DTG) were used. Due to the molecular structure of the sample and different physicochemical reactions, the thermogram data can be changed. The thermal behavior of the pure PEG, pure MP, and FPEGMP2 nanocomposite obtained by TGA-DTG analyses is shown in Figure 3. The thermogram for the pure polymer (PEG) shows a sharp maximum temperature at $433^{\circ} \mathrm{C}$ with $97.6 \%$ weight loss. The TGA curves of free MP (Figure 3(b)) show three stages of weight loss over the temperature range from $25^{\circ} \mathrm{C}$ to $1000^{\circ} \mathrm{C}$. The crystalline water was removed at $158^{\circ} \mathrm{C}$ with a total weight loss of $11 \%$. The second stage shows the sharp mass reduction at temperature maxima of $328^{\circ} \mathrm{C}$ with the weight losses of $31.2 \%$, presumably due to the decomposition of 6-mercaptopurine which agrees well with the previous study. The mass fragmentation and the thermal decomposition process are not exactly the same; therefore, the weight loss observed may be due to the loss of an HCS group at this step. The third stage was followed at $663^{\circ} \mathrm{C}$ with the weight losses of $56.6 \%$ [40].

The FPEGMP-2 nanocomposite (Figure 3(c)) shows the mass reduction starting from $43^{\circ} \mathrm{C}$ and completed at $940^{\circ} \mathrm{C}$ with four-weight losses $\left(43-170^{\circ} \mathrm{C}, 3.7 \%\right.$; $185-334^{\circ} \mathrm{C}, 6.9 \%$; $329-504^{\circ} \mathrm{C}, 20.7 \%$; and finally $522-940^{\circ} \mathrm{C}, 32.8 \%$ ). The first stage of weight loss might be due to the removal of adsorbed water. The onsets of decomposition of free MP, FNPs, and uncoated PEG was observed between 185 and $334^{\circ} \mathrm{C}$. A sharp peak in the region of $329-504^{\circ} \mathrm{C}$ might be due to the decomposition of PEG coated with MP, free drug MP, and FPEGMP-2 nanocomposite. Finally, the last stage was observed in the region of $522-910^{\circ} \mathrm{C}$ which may be due to the decomposition of free drug and FPEGMP-2 nanocomposite. Therefore, due to the coating process the thermal stability of MP in FPEGMP-2 nanocomposite was enhanced.

5.4. Magnetic Properties. Superparamagnetic property is required for magnetic targeting carriers and biomedical applications [15]; therefore, the magnetic performance of the FNPs (Figure 4(a)) and FPEGMP-2 (Figure 4(b)) was determined using a vibrating sample magnetometer at room temperature. As can be observed, the saturation magnetization of magnetite nanoparticles was about $54.64 \mathrm{emu} / \mathrm{g}$ compared to 33.62 for FPEGMP-2 nanocomposite, which is in good 


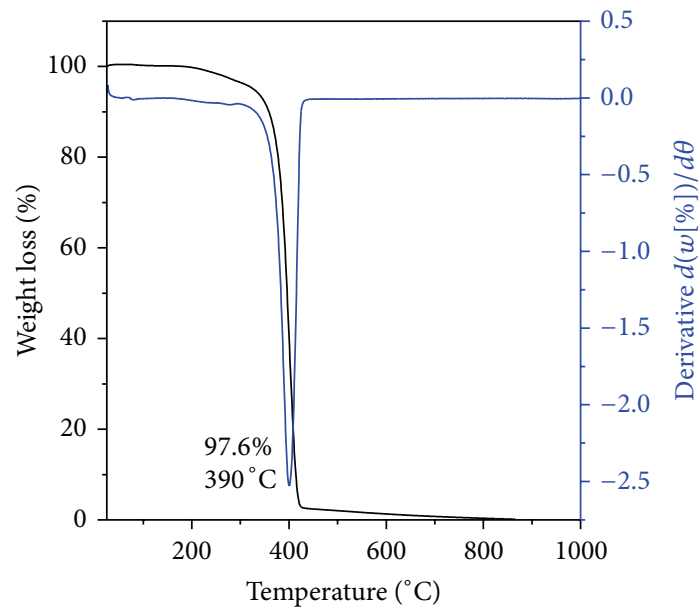

(a)

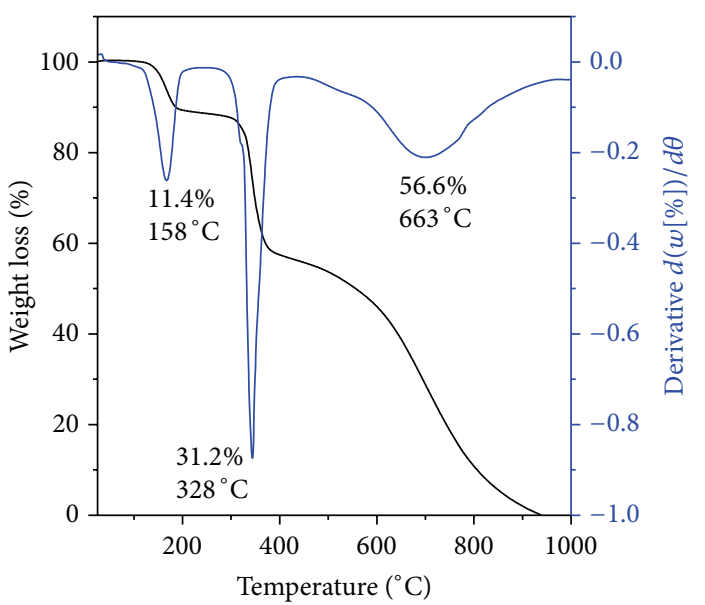

(b)

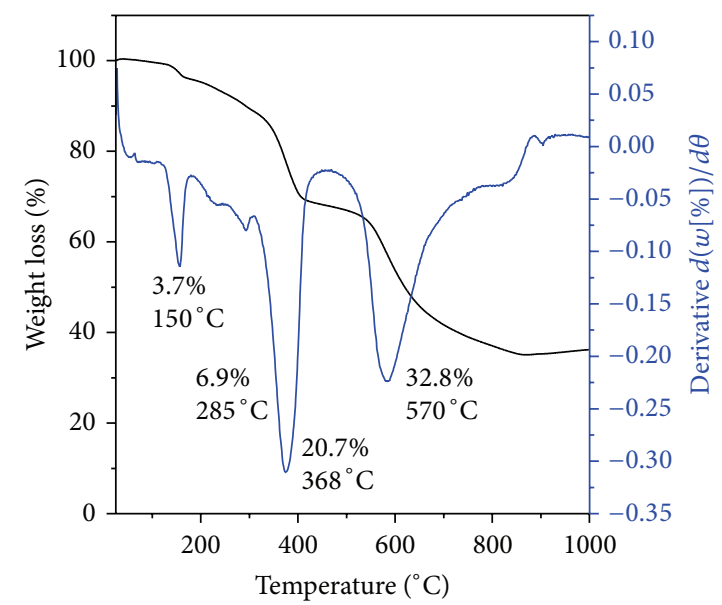

(c)

FIgUre 3: TGA of (a) pure PEG, (b) pure MP, and (c) FPEGMP-2 nanocomposite.

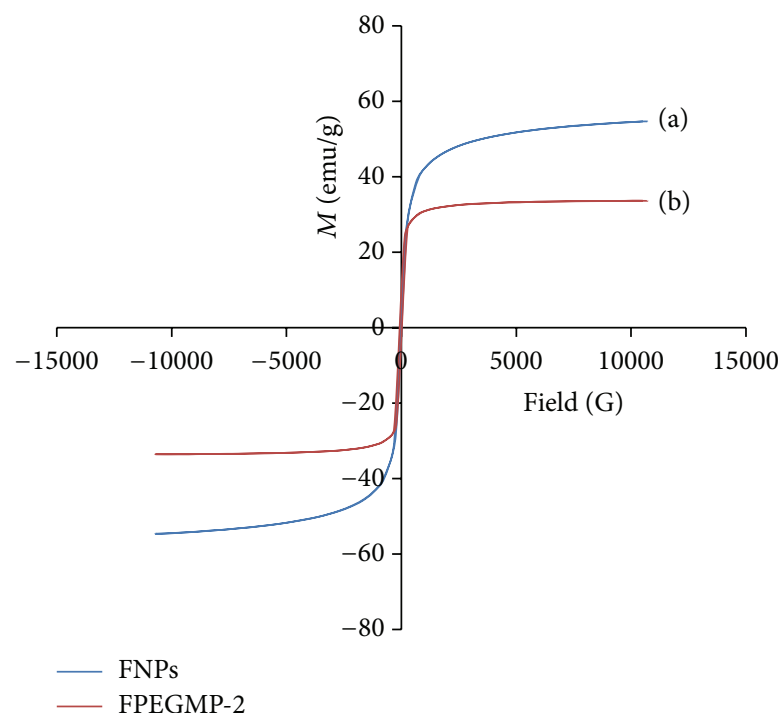

FIgURE 4: Magnetization plots of (a) FNPs and (b) FPEGMP-2 nanocomposite.
TABLE 1: Magnetic properties of FNPs and FPEGMP-2 nanocomposite.

\begin{tabular}{lccc}
\hline Samples & $M_{S}(\mathrm{emu} / \mathrm{g})$ & $M_{r}(\mathrm{emu} / \mathrm{g})$ & $H c(\mathrm{G})$ \\
\hline FNPs & 54.641 & 1.2314 & 20.655 \\
FPEGMP-2 & 38.635 & 0.5860 & 23.220 \\
\hline
\end{tabular}

agreement with previous works $[15,36,41,42]$. The decrease of saturation magnetization was only due to the existence of coated materials on the surface of magnetite nanoparticles, which causes the exchange of electrons between the surface of Fe atoms and the PEG polymers $[8,43]$. Due to the method of synthesis and the particle size, the saturation magnetization of bare iron oxide can be changed. Therefore, the value of saturation magnetization is usually lower than the theoretical value expected [44-46].

The magnetization curves show narrow hysteresis for both samples, revealing that they were soft magnets with superparamagnetic properties [47]. Table 1 listed the saturation magnetization $\left(M_{s}\right)$, remanent magnetization $\left(M_{r}\right)$, and 

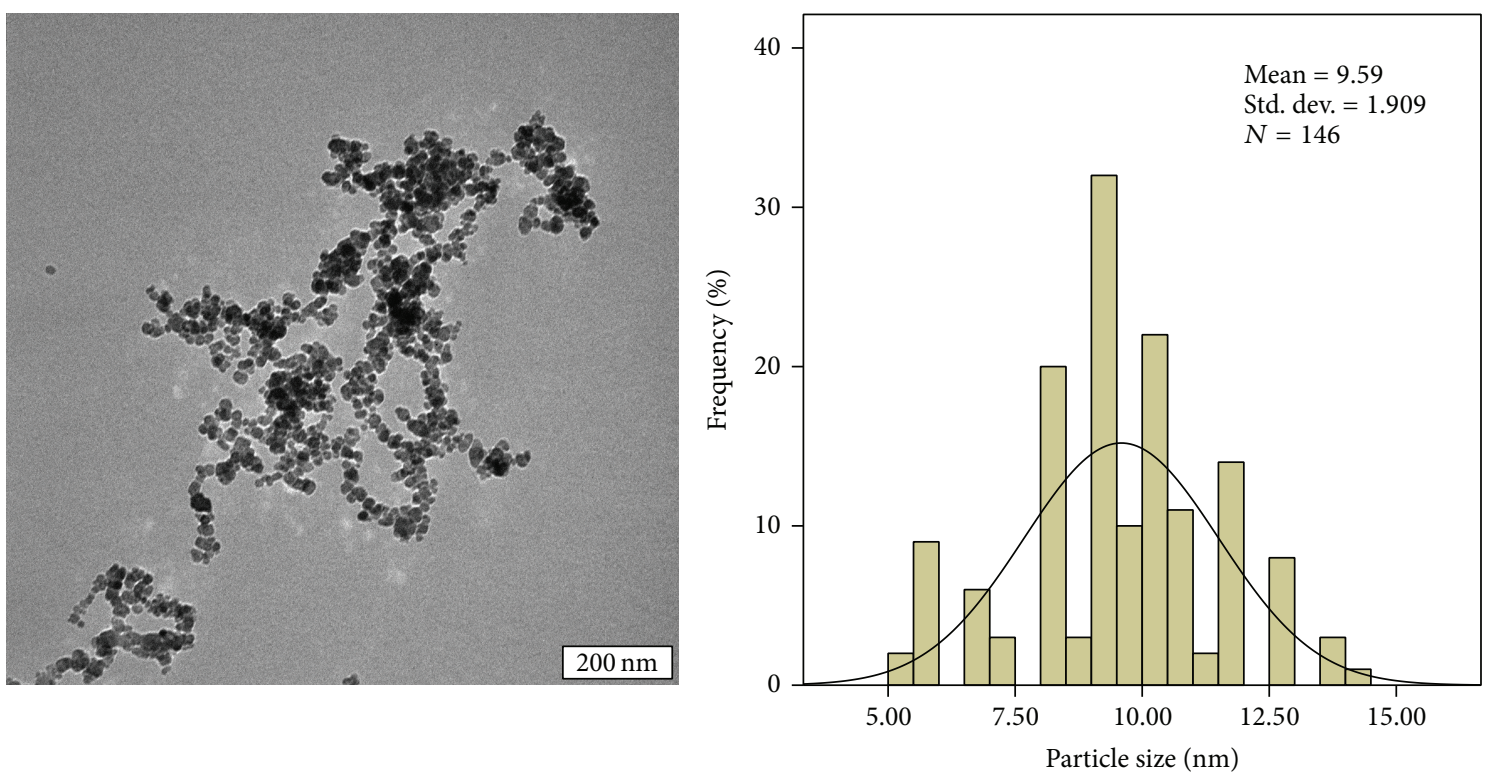

(a)
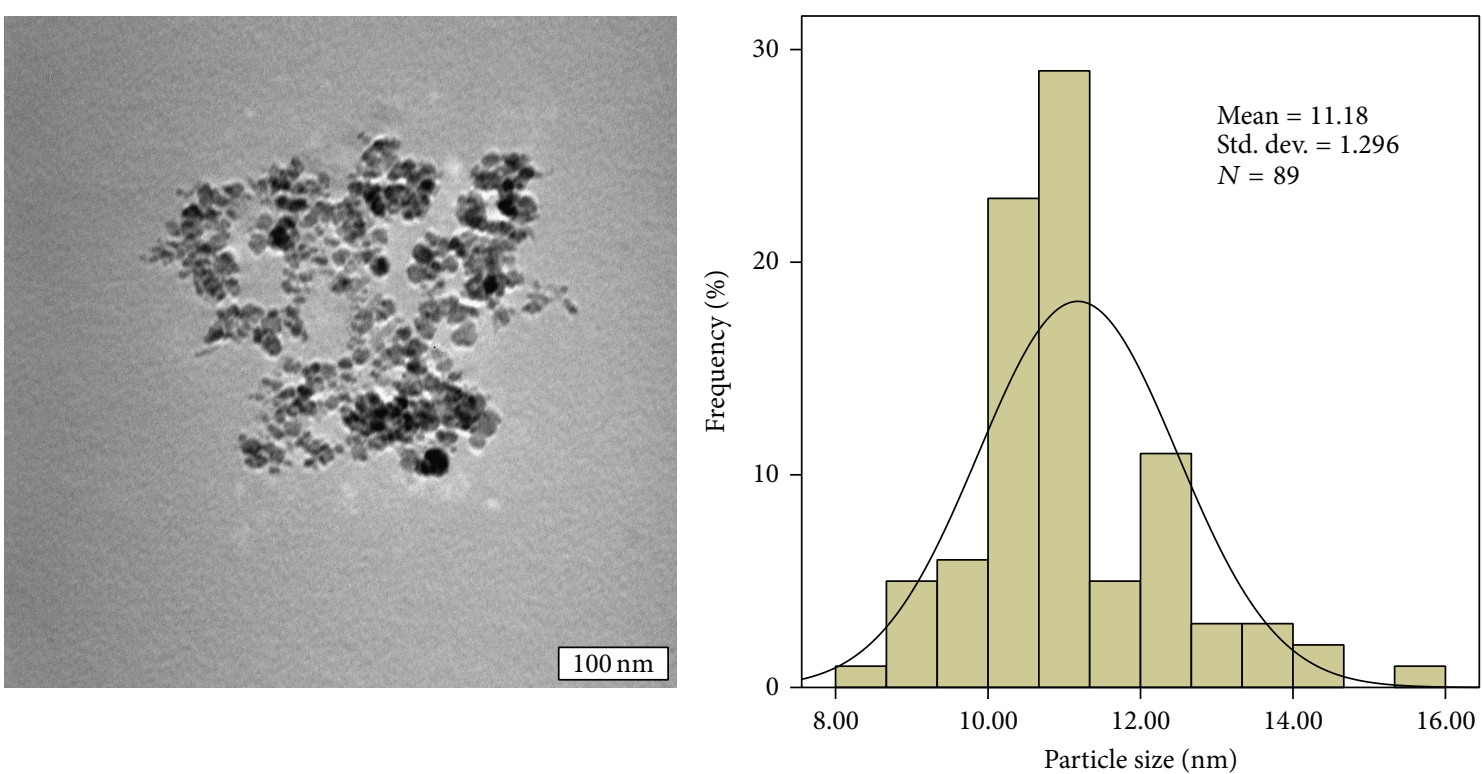

(b)

FIGURE 5: TEM micrographs of (a) iron oxide magnetite nanoparticles with $200 \mathrm{~nm}$ microbar and the particle size distribution, (b) FPEGMP-2 nanocomposite with $100 \mathrm{~nm}$ microbar and the particle size distribution.

coercivity $\left(H_{c}\right)$ values which were obtained from the magnetization curves. Due to a good magnetism property (high saturation magnetization) even after coating procedure, the FPEGMP-2 nanocomposite can be easily separated with the help of the external magnetic field [34]; therefore, FPEGMP-2 can be used in biomedical applications.

\subsection{Particle Size and Size Distribution Properties. Figure 5} shows the size and shape of the naked FNPs and FPEGMP2 nanocomposite. The particle size distribution was determined by measuring the diameters of around 100 nanoparticles randomly through the TEM images and using a UTHSCSA ImageTool software. It can be observed that the nanoparticles are well-dispersed and uniform in size and shape although some agglomerate clusters exist due to the magnetization effect [15]. Figures 5(a) and 5(b) show that the pristine FNPs and FPEGMP-2 nanocomposite were nearly spherical in shape and were essentially monodisperse. The average size of FNPs before and after coating is generally similar, around $10 \pm 2 \mathrm{~nm}$ and $11 \pm 1 \mathrm{~nm}$, respectively. From such small differences in the size of FNPs and FPEGMP-2 nanocomposite it can be found that the PEG-MP was 
TABLE 2: Correlation coefficient, rate constant, and half-time obtained by fitting the data of the release of MP from FPEGMP-2 nanocomposite into phosphate-buffered solution at pH 4.8 and 7.4.

\begin{tabular}{lccccc}
\hline Aqueous solution & Saturated release $\%$ & $\begin{array}{c}R^{2} \\
\text { Pseudo-first } \\
\text { order }\end{array}$ & $\begin{array}{c}\text { Pseudo-second } \\
\text { order }\end{array}$ & $\begin{array}{c}\text { Parabolic } \\
\text { diffusion }\end{array}$ & $\begin{array}{c}\text { Rate constant }(k)^{\mathrm{a}} \\
(\mathrm{mg} / \mathrm{min})\end{array}$ \\
\hline pH 7.4 & 59.6 & 0.4017 & 0.9990 & 0.4876 & $1.89 \times 10^{-4}$ \\
pH 4.8 & 97.2 & 0.9168 & 0.9950 & 0.9567 & $5.59 \times 10^{-4}$ \\
\hline
\end{tabular}

${ }^{\mathrm{a}}$ Estimated using pseudo-second order kinetics.

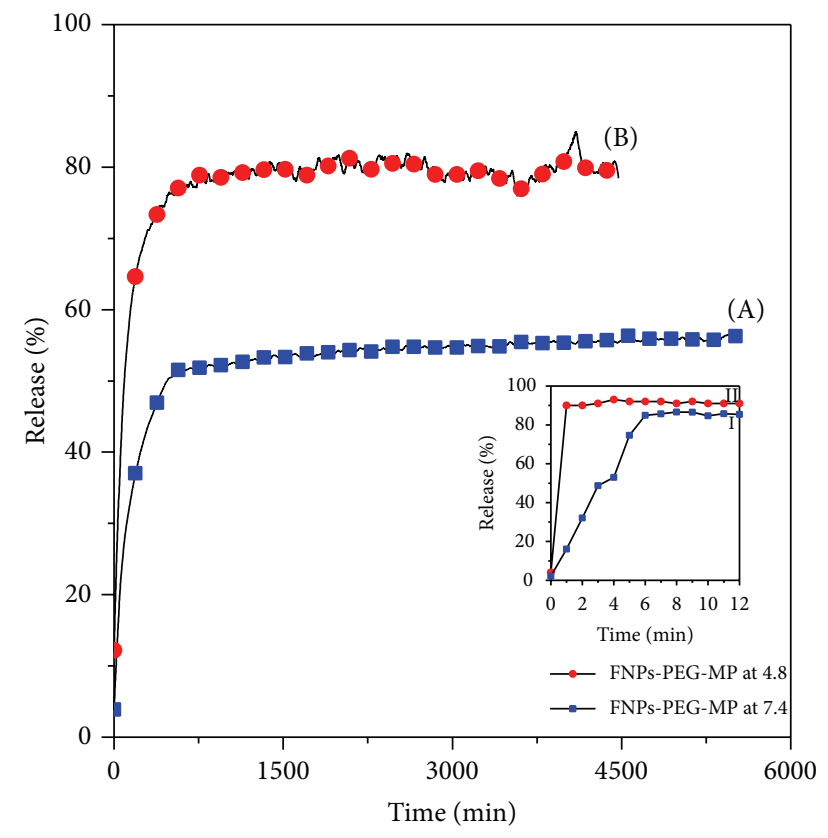

FIGURE 6: Release profiles of MP from the FPEGMP-2 nanocomposite into (A) phosphate buffered solution at $\mathrm{pH} 7.4$ and (B) phosphate buffered solution at $\mathrm{pH}$ 4.8. The inset shows the release profiles of MP from its physical mixture of FNPs-PEG-MP into phosphate buffered solution (I) at $\mathrm{pH} 7.4$ and (II) at $\mathrm{pH} 4.8$.

successfully coated on the surface of magnetite nanoparticles $[3,48]$.

5.6. Release Study of MP. Through a UV spectrophotometer and a calibration curve equation the percentage of MP loading into FPEGMP-2 nanocomposite was measured to be around $5.6 \%$. The cumulative release profiles of MP from the FPEGMP-2 nanocomposites were investigated by adding the FPEGMP-2 nanocomposite into phosphate buffered solutions at $\mathrm{pH} 7.4$ and 4.8. Figure 6 shows the release profiles of MP from the abovementioned nanocomposite and the inset shows the MP release from a physical mixture of MP with $\mathrm{Fe}_{3} \mathrm{O}_{4}$-PEG into the same solutions. The release of MP from the physical mixture was found to be very fast, 4 and 7 minutes at $\mathrm{pH} 4.8$ and 7.4, respectively. This indicates that the release of $\mathrm{MP}$ is not in the sustained-release manner. On the other hand, the release of MP from FPEGMP-2 nanocomposite was much slower than that from the physical mixture, indicating a controlled release property of the latter.
It was found that the release rate of MP from FPEGMP2 is affected by the acidity of the media. Due to the "burst effect" [49] and other mechanisms, the release behavior of MP shows a fast release at the beginning, $67 \%$ for the first 4 hours, followed by a slower stage of $85 \%$ for the second 74 hours at $\mathrm{pH} 4.8$ (Figure 6(B)). At $\mathrm{pH} 7.4$, the release rates of MP are slower than that at $\mathrm{pH} 4.8$ and the maximum percentage release reaches about $56 \%$ at about 92 hours (Figure 6(A)). Therefore, the result reveals that the FPEGMP2 nanocomposite shows a good potential to be used as a drug delivery with controlled release property.

In order to obtain more insight into the mechanism of release of MP from FPEGMP-2 nanocomposite, three different kinetic models were used to fit the release data. The pseudo-first order kinetic equation [50] $\left(\ln \left(q_{e}-q_{t}\right)=\ln q_{e}-\right.$ $\left.k_{1} t\right)$ represents the release of MP from FPEGMP-2 nanocomposite and the decomposition rate depends on the amount of MP in the FPEGMP-2 nanocomposite. The other two kinetic models can be described by pseudo-second order model [51] which can be expressed in the form of $\left(t / q_{t}=1 / k_{2} q_{e}^{2}+t / q_{e}\right)$ and the parabolic diffusion model which can be represented as [52] $\left(1-M_{t} / M_{0}\right) / t=k t^{-0.5}+b$ equations. In pseudo-first order equation and the pseudo-second order kinetic model, the $q_{e}$ and $q_{t}$ are the equilibrium release rate and the release rate at time $t$, respectively. Also $k$, in all three models, is a constant and corresponding to the release amount. The $M_{0}$ and $M_{t}$ in parabolic equation are the drug content remained in FPEGMP-2 nanocomposite at release time 0 and $t$, respectively. Through the basis of these kinetic models, as mentioned earlier for the release kinetic data, it was found that the pseudo-second order kinetic model can be more satisfactory in order to describe the release behavior of 6-mercaptopurine from FPEGMP-2 nanocomposites compared to the other models used in this work (Figures 7(a) and 7(b) and Table 2).

5.7. In Vitro Bioassay. Figure 8 shows a dose-dependent effect of FNPs, MP, FPEGMP-0.5, and FPEGMP-2 nanocomposites. Pure MP showed a higher anticancer effect on the leukemic cell line compared to the other two nanocomposites (FPEGMP-0.5 and FPEGMP-2) within the tested doses. The uncoated iron oxide nanoparticles demonstrated sustained leukemic cell viability even in the presence of increased concentration. This finding is similar to a previous study done on both normal and cancerous cell lines exposed to iron oxide nanoparticles up to $30 \mu \mathrm{g} / \mathrm{mL}$ concentration, where more 


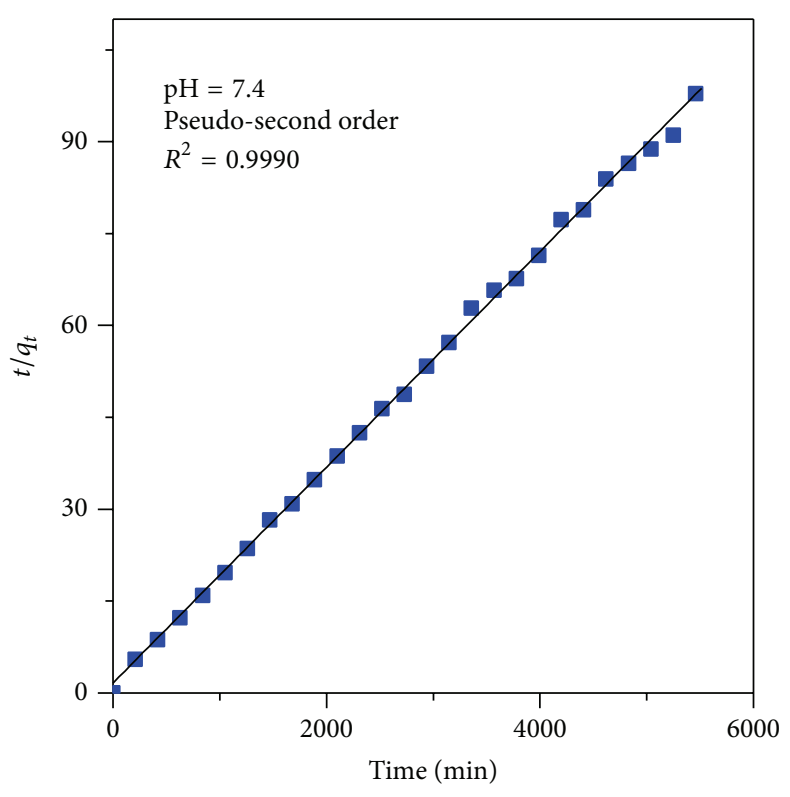

(a)

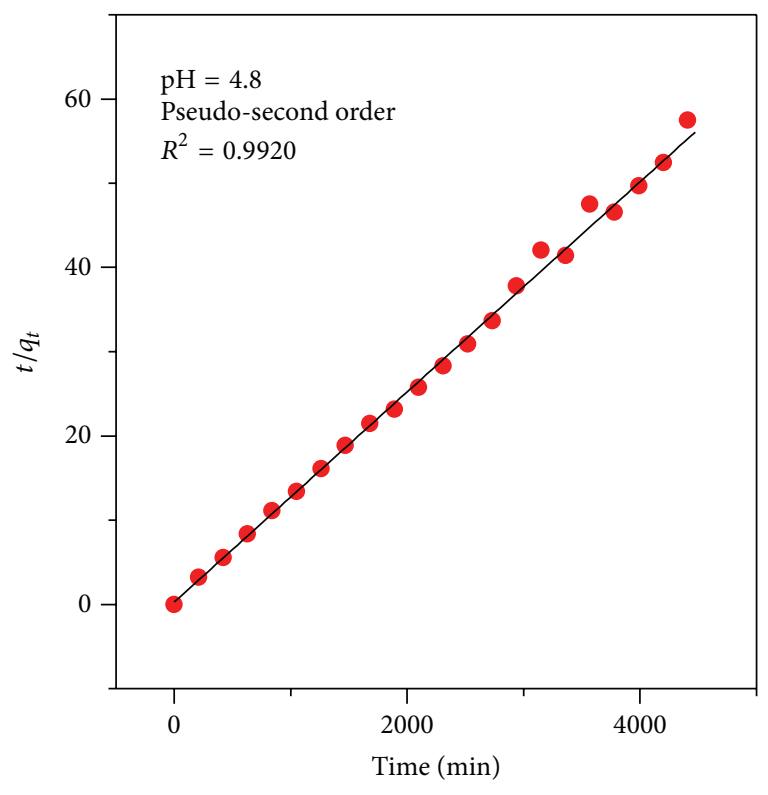

(b)

FIGURE 7: Fitting the data of MP release from FPEGMP-2 nanocomposite into phosphate buffered solution to the pseudo-second order kinetics for $\mathrm{pH} 7.4$ (a) and $\mathrm{pH} 4.8$ (b).

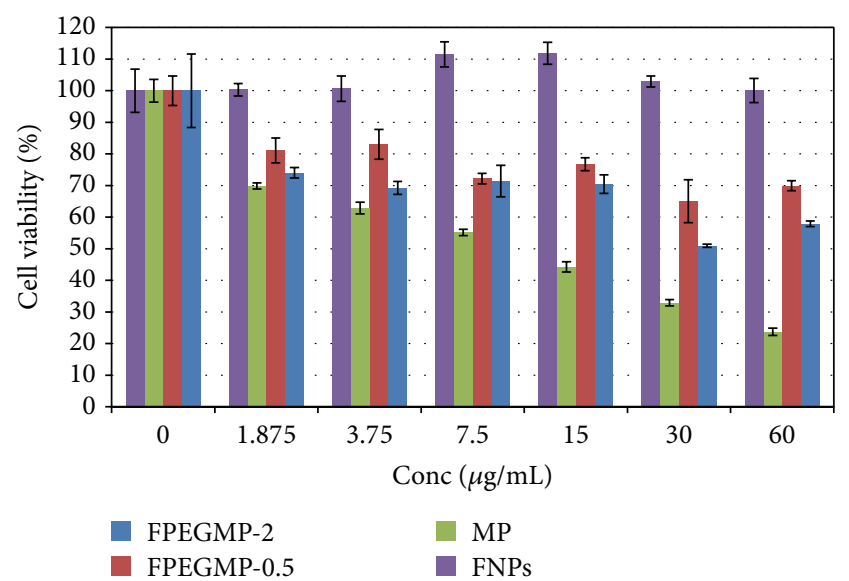

FIGURE 8: Showing in vitro cytotoxicity studies of WEHI-3B cells after 48 hours of exposure to free MP, iron oxide nanoparticles (FNPs), FPEGMP-0.5, and FPEGMP-2 nanocomposites. The two nanocomposites (FPEGMP-0.5 and FPEGMP-2) and pure MP showed continuous cell viability, decreased with each increase in dose. Their $\mathrm{IC}_{50}$ values were found to be $10 \pm 0.5 \mu \mathrm{g} / \mathrm{mL}, 30 \pm 3.0$ $\mu \mathrm{g} / \mathrm{mL}$, and $6.0 \pm 2.0 \mu \mathrm{g} / \mathrm{mL}$ for MP, FPEGMP-2, and FPEGMP0.5 , respectively, as obtained from the graph and calculated via regression analysis.

than $80 \%$ of the cell survived the nanoparticles treatment $[1,53]$.

The two nanocomposites, FPEGMP-0.5 and FPEGMP-2, showed lower anticancer activity in almost all the concentration tested compared to pure MP. However, in our previous study [1], we reported enhanced anticancer activity of the 6mercaptopurine on the same leukemic cell line after coating with FNPs-chitosan. This finding concurred with other previous work [54], where PVP-coated silver nanoparticles induced greater cytotoxicity than citrate-coated particles. Surface coating of nanoparticles has been shown to affect affinity for cell surface adhesion as well as dissolution [54]. In another related study chitosan-coated magnetic nanoparticles showed higher cell capture rate than starch coating [55]. The capture rate on fibro sarcoma cell lines was found to be 73.4 and $64.1 \%$ for chitosan and starch, respectively.

Anticancer activity of FPEGMP-2 nanocomposite was found to be slightly higher than FPEGMP-0.5 in a dosedependent manner on the leukemic cell lines (Figure 8). This may be attributed to the differences in percentage of 6-mercaptopurine between the two nanocomposites. Thus, choice of coating material as well as percentage loading of active agent on a nanocarrier was shown to affect the activity of the resulting materials.

\section{Conclusion}

The iron oxide nanoparticles prepared via coprecipitation method are of magnetite material with the mean size of $10 \mathrm{~nm}$. Similarly, the PEG-coated nanoparticles, FPEGMP2 , are composed of pure magnetite core with particle mean size of $11 \mathrm{~nm}$. The attachment of PEG-MP in the latter onto the surface of the former was supported by FTIR findings. Vibrating sample magnetometer studies confirm the superparamagnetic properties of iron oxide nanoparticles (FNPs) and the FPEGMP-2 nanocomposite. The thermal stability of the resulting nanocomposite (FPEGMP-2) compared to the pure drug (MP) was found to improve 
after the coating process. The release behavior of MP from FPEGMP-2 nanocomposite into phosphate buffered solution was found to be of controlled manner with release percentage of about $60 \%$ and $97 \%$ when exposed to $\mathrm{pH} 7.4$ and 4.8 , respectively. It was found that FPEGMP-2 demonstrated slightly higher anticancer activity on leukemic WEHI-3B cell lines than the FPEGMP-0.5 nanocomposite in a dosedependent manner. The uncoated FNPs demonstrated sustained leukemic cell viability even in the presence of increased concentration. This may be due to the differences in percentage of 6-mercaptopurine between these two nanocomposites (FPEGMP-0.5 and FPEGMP-2). Therefore, the choice of coating material as well as percentage loading of the active agent on a nanocarrier was shown to affect the cytotoxicity activity.

\section{Conflict of Interests}

The authors declare that there is no conflict of interests regarding the publication of this paper.

\section{Acknowledgment}

Funding for this research was provided by the Ministry of Science, Technology and Innovation of Malaysia (MOSTI) under National Nanotechnology Initiative, Grant NND/NA/(1)/TD11- 010 (Vot no. 5489100).

\section{References}

[1] D. Dorniani, M. Z. bin Hussein, A. U. Kura, S. Fakurazi, A. H. Shaari, and Z. Ahmad, "Preparation and characterization of 6-mercaptopurine-coated magnetite nanoparticles as a drug delivery system," Drug Design, Development and Therapy, vol. 7, pp. 1015-1026, 2013.

[2] M. Y. Ghotbi and M. Z. Bin Hussein, "Controlled release study of an anti-carcinogenic agent, gallate from the surface of magnetite nanoparticles," Journal of Physics and Chemistry of Solids, vol. 73, no. 7, pp. 936-942, 2012.

[3] J. Qu, G. Liu, Y. Wang, and R. Hong, "Preparation of $\mathrm{Fe}_{3} \mathrm{O}_{4}$ chitosan nanoparticles used for hyperthermia," Advanced Powder Technology, vol. 21, no. 4, pp. 461-467, 2010.

[4] C. C. Berry, S. Wells, S. Charles, and A. S. G. Curtis, "Dextran and albumin derivatised iron oxide nanoparticles: influence on fibroblasts in vitro," Biomaterials, vol. 24, no. 25, pp. 4551-4557, 2003.

[5] S. Mornet, S. Vasseur, F. Grasset, and E. Duguet, "Magnetic nanoparticle design for medical diagnosis and therapy," Journal of Materials Chemistry, vol. 14, no. 14, pp. 2161-2175, 2004.

[6] Y.-M. Huh, Y.-W. Jun, H.-T. Song et al., "In vivo magnetic resonance detection of cancer by using multifunctional magnetic nanocrystals," Journal of the American Chemical Society, vol. 127, no. 35, pp. 12387-12391, 2005.

[7] R. Matsuno, K. Yamamoto, H. Otsuka, and A. Takahara, "Polystyrene- and poly(3-vinylpyridine)-grafted magnetite nanoparticles prepared through surface-initiated nitroxide-mediated radical polymerization," Macromolecules, vol. 37, no. 6, pp. 2203-2209, 2004.

[8] Y. Ge, Y. Zhang, J. Xia et al., "Effect of surface charge and agglomerate degree of magnetic iron oxide nanoparticles on $\mathrm{KB}$ cellular uptake in vitro," Colloids and Surfaces B: Biointerfaces, vol. 73, no. 2, pp. 294-301, 2009.

[9] I. Safarik and M. Safarikova, "Magnetic techniques for the isolation and purification of proteins and peptides," BioMagnetic Research and Technology, vol. 2, article 7, 2004.

[10] D. Li, W. Y. Teoh, C. Selomulya, R. C. Woodward, R. Amal, and B. Rosche, "Flame-sprayed superparamagnetic bare and silicacoated maghemite nanoparticles: synthesis, characterization, and protein adsorption-desorption," Chemistry of Materials, vol. 18, no. 26, pp. 6403-6413, 2006.

[11] W. H. de Jong and P. J. A. Borm, "Drug delivery and nanoparticles: applications and hazards," International Journal of Nanomedicine, vol. 3, no. 2, pp. 133-149, 2008.

[12] J. K. Oh and J. M. Park, "Iron oxide-based superparamagnetic polymeric nanomaterials: design, preparation, and biomedical application," Progress in Polymer Science, vol. 36, no. 1, pp. 168$189,2011$.

[13] T. K. Jain, M. A. Morales, S. K. Sahoo, D. L. Leslie-Pelecky, and V. Labhasetwar, "Iron oxide nanoparticles for sustained delivery of anticancer agents," Molecular Pharmaceutics, vol. 2, no. 3, pp. 194-205, 2005.

[14] V. Ström, K. Hultenby, C. Grüttner, J. Teller, B. Xu, and J. Holgersson, "A novel and rapid method for quantification of magnetic nanoparticle-cell interactions using a desktop susceptometer," Nanotechnology, vol. 15, no. 5, pp. 457-466, 2004.

[15] J. B. Qu, H. H. Shao, G. L. Jing, and F. Huang, "PEG-chitosancoated iron oxide nanoparticles with high saturated magnetization as carriers of 10-hydroxycamptothecin: preparation, characterization and cytotoxicity studies," Colloids and Surfaces B: Biointerfaces, vol. 102, pp. 37-44, 2013.

[16] A. Petri-Fink, B. Steitz, A. Finka, J. Salaklang, and H. Hofmann, "Effect of cell media on polymer coated superparamagnetic iron oxide nanoparticles (SPIONs): colloidal stability, cytotoxicity, and cellular uptake studies," European Journal of Pharmaceutics and Biopharmaceutics, vol. 68, no. 1, pp. 129-137, 2008.

[17] D. Bazile, C. Prud'Homme, M.-T. Bassoullet, M. Marlard, G. Spenlehauer, and M. Veillard, "Stealth Me.PEG-PLA nanoparticles avoid uptake by the mononuclear phagocytes system," Journal of Pharmaceutical Sciences, vol. 84, no. 4, pp. 493-498, 1995.

[18] S. H. Hussein-Al-Ali, P. Arulselvan, S. Fakurazi, M. Z. Hussein, and D. Dorniani, "Arginine-chitosan-and argininepolyethylene glycol-conjugated superparamagnetic nanoparticles: preparation, cytotoxicity andcontrolled-release," Journal of Biomaterials Applications. In press.

[19] T. Niidome, M. Yamagata, Y. Okamoto et al., "PEG-modified gold nanorods with a stealth character for in vivo applications," Journal of Controlled Release, vol. 114, no. 3, pp. 343-347, 2006.

[20] M. Mahmoudi, A. Simchi, M. Imani, A. S. Milani, and P. Stroeve, "Optimal design and characterization of superparamagnetic iron oxide nanoparticles coated with polyvinyl alcohol for targeted delivery and imaging," Journal of Physical Chemistry B, vol. 112, no. 46, pp. 14470-14481, 2008.

[21] D. Dorniani, A. U. Kura, S. H. Hussein-Al-Ali et al., "In vitro sustained release study of gallic acid coated with magnetite-PEG and magnetite-PVA for drug delivery system," The Scientific World Journal, vol. 2014, Article ID 416354, 11 pages, 2014.

[22] D. Dorniani, M. Z. B. Hussein, A. U. Kura, S. Fakurazi, A. H. Shaari, and Z. Ahmad, "Sustained release of prindopril erbumine from its chitosan-coated magnetic nanoparticles for biomedical applications," International Journal of Molecular Sciences, vol. 14, pp. 23639-23653, 2013. 
[23] S. Laurent, D. Forge, M. Port et al., "Magnetic iron oxide nanoparticles: synthesis, stabilization, vectorization, physicochemical characterizations and biological applications," Chemical Reviews, vol. 108, no. 6, pp. 2064-2110, 2008.

[24] E. H. Kim, Y. Ahn, and H. S. Lee, "Biomedical applications of superparamagnetic iron oxide nanoparticles encapsulated within chitosan," Journal of Alloys and Compounds, vol. 434-435, pp. 633-636, 2007.

[25] D. Dorniani, M. Z. B. Hussein, A. U. Kura, S. Fakurazi, A. H. Shaari, and Z. Ahmad, "Preparation of $\mathrm{Fe}_{3} \mathrm{O}_{4}$ magnetic nanoparticles coated with gallic acid for drug delivery," International Journal of Nanomedicine, vol. 7, pp. 5745-5756, 2012.

[26] A. Moore, E. Marecos, A. Bogdanov Jr., and R. Weissleder, "Tumoral distribution of long-circulating dextran-coated iron oxide nanoparticles in a rodent model," Radiology, vol. 214, no. 2, pp. 568-574, 2000.

[27] T.-J. Chen, T.-H. Cheng, C.-Y. Chen et al., “Targeted herceptindextran iron oxide nanoparticles for noninvasive imaging of HER2/neu receptors using MRI," Journal of Biological Inorganic Chemistry, vol. 14, no. 2, pp. 253-260, 2009.

[28] H. Lee, H. Shao, Y. Huang, and B. Kwak, "Synthesis of MRI contrast agent by coating superparamagnetic iron oxide with chitosan," IEEE Transactions on Magnetics, vol. 41, no. 10, pp. 4102-4104, 2005.

[29] S.-J. Xia, Z.-M. Ni, Q. Xu, B.-X. Hu, and J. Hu, "Layered double hydroxides as supports for intercalation and sustained release of antihypertensive drugs," Journal of Solid State Chemistry, vol. 181, no. 10, pp. 2610-2619, 2008.

[30] C. Ribeiro, G. G. C. Arizaga, F. Wypych, and M.-R. Sierakowski, "Nanocomposites coated with xyloglucan for drug delivery: in vitro studies," International Journal of Pharmaceutics, vol. 367, no. 1-2, pp. 204-210, 2009.

[31] H. Zhang, K. Zou, S. Guo, and X. Duan, "Nanostructural druginorganic clay composites: structure, thermal property and in vitro release of captopril-intercalated $\mathrm{Mg}$-Al-layered double hydroxides," Journal of Solid State Chemistry, vol. 179, no. 6, pp. 1792-1801, 2006.

[32] C. Wang, L. Feng, H. Yang et al., "Graphene oxide stabilized polyethylene glycol for heat storage," Physical Chemistry Chemical Physics, vol. 14, pp. 13233-13238, 2012.

[33] M. F. Calmon, A. T. de Souza, N. M. Candido et al., "A systematic study of transfection efficiency and cytotoxicity in HeLa cells using iron oxide nanoparticles prepared with organic and inorganic bases," Colloids and Surfaces B: Biointerfaces, vol. 100, pp. 177-184, 2012.

[34] C. Yuwei and W. Jianlong, "Preparation and characterization of magnetic chitosan nanoparticles and its application for $\mathrm{Cu}(\mathrm{II})$ removal," Chemical Engineering Journal, vol. 168, no. 1, pp. 286292, 2011.

[35] Y. Hou, Z. Xu, and S. Sun, "Controlled synthesis and chemical conversions of $\mathrm{FeO}$ nanoparticles," Angewandte ChemieInternational Edition, vol. 46, no. 33, pp. 6329-6332, 2007.

[36] S. Kayal and R. V. Ramanujan, "Doxorubicin loaded PVA coated iron oxide nanoparticles for targeted drug delivery," Materials Science and Engineering C, vol. 30, no. 3, pp. 484-490, 2010.

[37] J. Sangeetha and J. Philip, "The interaction, stability and response to an external stimulus of iron oxide nanoparticlecasein nanocomplexes," Colloids and Surfaces A: Physicochemical and Engineering Aspects, vol. 406, pp. 52-60, 2012.

[38] K. Shameli, M. Bin Ahmad, S. D. Jazayeri et al., "Synthesis and characterization of polyethylene glycol mediated silver nanoparticles by the green method," International Journal of Molecular Sciences, vol. 13, pp. 6639-6650, 2012.

[39] R. Acevedo-Chávez, M. E. Costas, and R. Escudero, "Magnetic study of the novel polynuclear compound $[\mathrm{Cu}(\mathrm{II})(6-$ mercaptopurinolate $\left.\left.{ }^{2-}\right)\right]_{n}$," Journal of Solid State Chemistry, vol. 132, no. 1, pp. 78-87, 1997.

[40] J. Bariyanga and A. S. Luyt, "Synthesis, fourier transform infrared, nuclear magnetic resonance and thermal analysis of sodium and platinum complexes of 6-mercaptopurine," Journal of Molecular Structure, vol. 559, no. 1-3, pp. 49-54, 2001.

[41] G. Dodi, D. Hritcu, G. Lisa, and M. I. Popa, "Core-shell magnetic chitosan particles functionalized by grafting: synthesis and characterization," Chemical Engineering Journal, vol. 203, pp. 130-141, 2012.

[42] J. Feng, J. Mao, X. Wen, and M. Tu, "Ultrasonic-assisted in situ synthesis and characterization of superparamagnetic $\mathrm{Fe}_{3} \mathrm{O}_{4}$ nanoparticles," Journal of Alloys and Compounds, vol. 509, no. 37, pp. 9093-9097, 2011.

[43] R. Kumar, B. S. Inbaraj, and B. H. Chen, "Surface modification of superparamagnetic iron nanoparticles with calcium salt of $\operatorname{poly}(\gamma$-glutamic acid) as coating material," Materials Research Bulletin, vol. 45, no. 11, pp. 1603-1607, 2010.

[44] J. Mürbe, A. Rechtenbach, and J. Töpfer, "Synthesis and physical characterization of magnetite nanoparticles for biomedical applications," Materials Chemistry and Physics, vol. 110, no. 2-3, pp. 426-433, 2008.

[45] A. Debrassi, A. F. Corrêa, T. Baccarin et al., "Removal of cationic dyes from aqueous solutions using $N$-benzylO-carboxymethylchitosan magnetic nanoparticles," Chemical Engineering Journal, vol. 183, pp. 284-293, 2012.

[46] M. Arruebo, R. Fernández-Pacheco, M. R. Ibarra, and J. Santamaría, "Magnetic nanoparticles for drug delivery", Nano Today, vol. 2, no. 3, pp. 22-32, 2007.

[47] D.-H. Chen and M.-H. Liao, "Preparation and characterization of YADH-bound magnetic nanoparticles," Journal of Molecular Catalysis B: Enzymatic, vol. 16, no. 5-6, pp. 283-291, 2002.

[48] L.-Y. Zhang, X.-J. Zhu, H.-W. Sun, G.-R. Chi, J.-X. Xu, and Y.-L. Sun, "Control synthesis of magnetic $\mathrm{Fe}_{3} \mathrm{O}_{4}$-chitosan nanoparticles under UV irradiation in aqueous system," Current Applied Physics, vol. 10, no. 3, pp. 828-833, 2010.

[49] X. Huang and C. S. Brazel, "On the importance and mechanisms of burst release in matrix-controlled drug delivery systems," Journal of Controlled Release, vol. 73, no. 2-3, pp. 121-136, 2001.

[50] S. H. Hussein-Al-Ali, M. Al-Qubaisi, M. Z. Hussein, M. Ismail, Z. Zainal, and M. N. Hakim, "In vitro inhibition of histamine release behavior of cetirizine intercalated into $\mathrm{Zn} / \mathrm{Al}$ and Mg/Al-layered double hydroxides," International Journal of Molecular Sciences, vol. 13, pp. 5899-5916, 2012.

[51] L. Dong, L. Yan, W.-G. Hou, and S.-J. Liu, "Synthesis and release behavior of composites of camptothecin and layered double hydroxide," Journal of Solid State Chemistry, vol. 183, no. 8, pp. 1811-1816, 2010.

[52] Y.-S. Ho and A. E. Ofomaja, "Pseudo-second-order model for lead ion sorption from aqueous solutions onto palm kernel fiber," Journal of Hazardous Materials, vol. 129, no. 1-3, pp. 137142, 2006.

[53] B. Ankamwar, T. C. Lai, J. H. Huang et al., "Biocompatibility of $\mathrm{Fe}_{3} \mathrm{O}_{4}$ nanoparticles evaluated by in vitro cytotoxicity assays using normal, glia and breast cancer cells," Nanotechnology, vol. 21, no. 7, Article ID 075102, 2010. 
[54] K. C. Nguyen, V. L. Seligy, A. Massarsky et al., "Comparison of toxicity of uncoated and coated silver nanoparticles," Journal of Physics: Conference Series, vol. 429, Article ID 012025, 2013.

[55] D.-H. Kim, K.-N. Kim, K.-M. Kim, and Y.-K. Lee, “Targeting to carcinoma cells with chitosan- and starch-coated magnetic nanoparticles for magnetic hyperthermia," Journal of Biomedical Materials Research A, vol. 88, no. 1, pp. 1-11, 2009. 

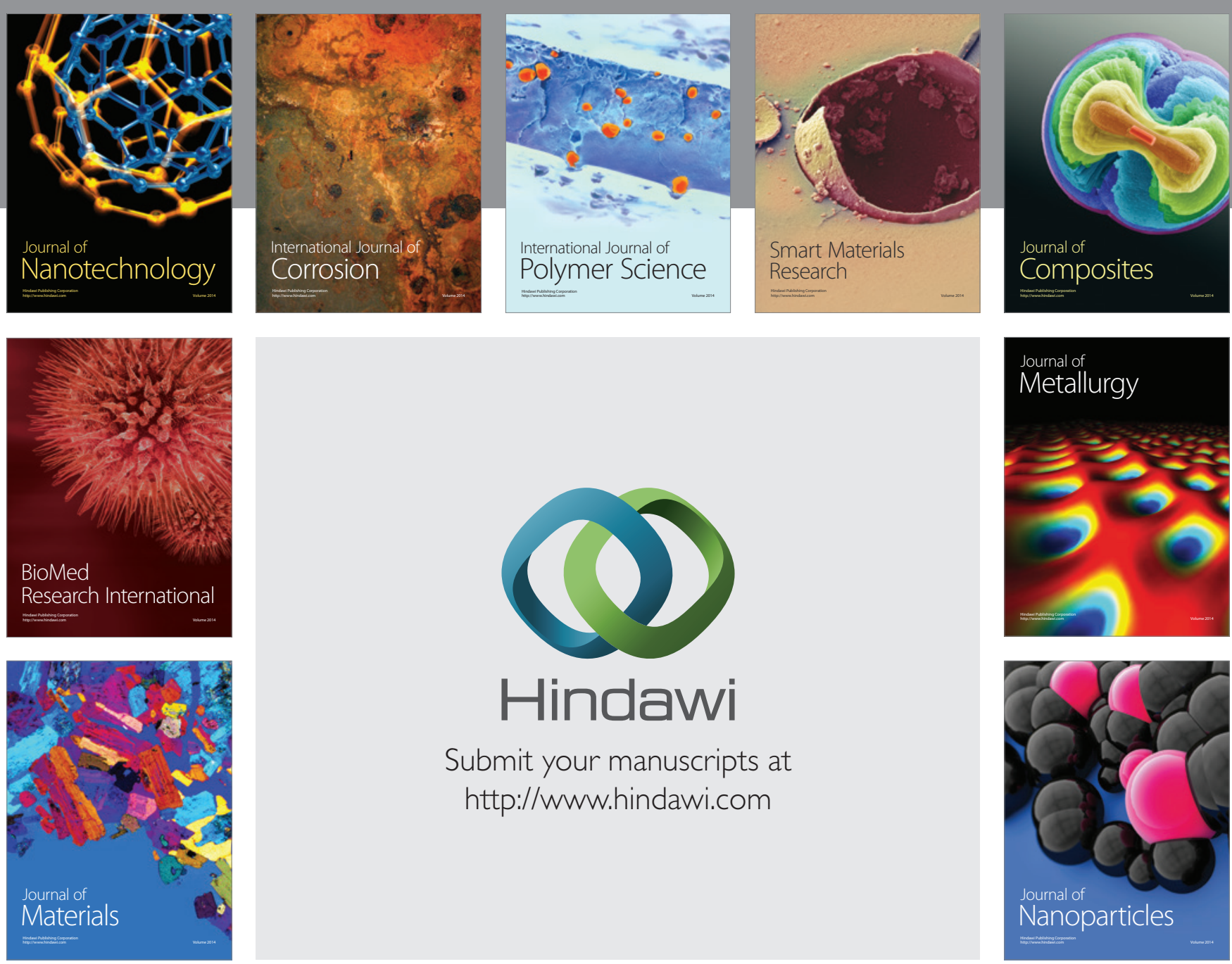

Submit your manuscripts at http://www.hindawi.com
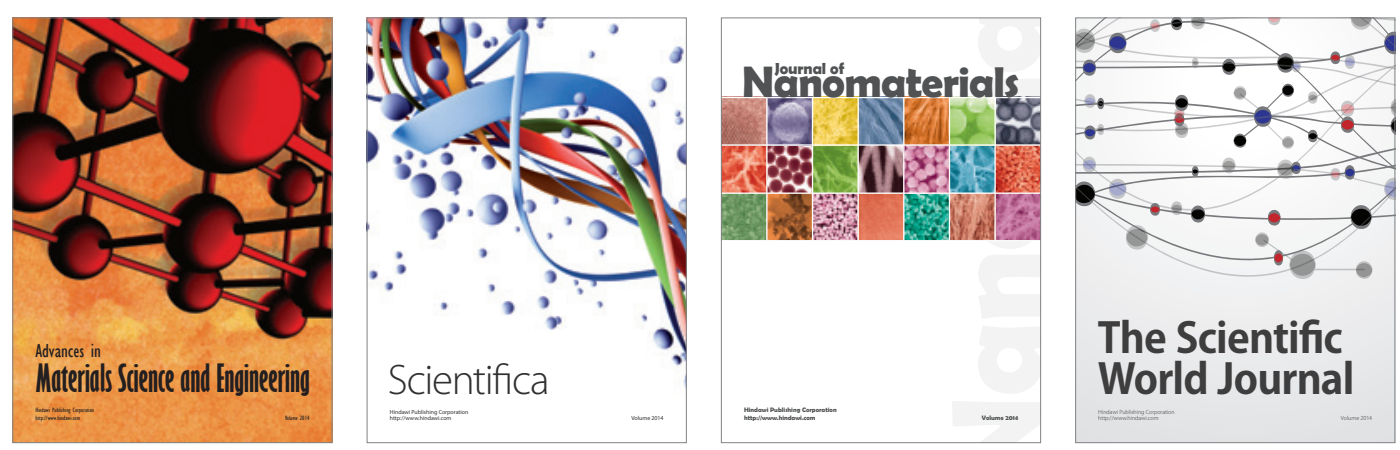

\section{The Scientific World Journal}
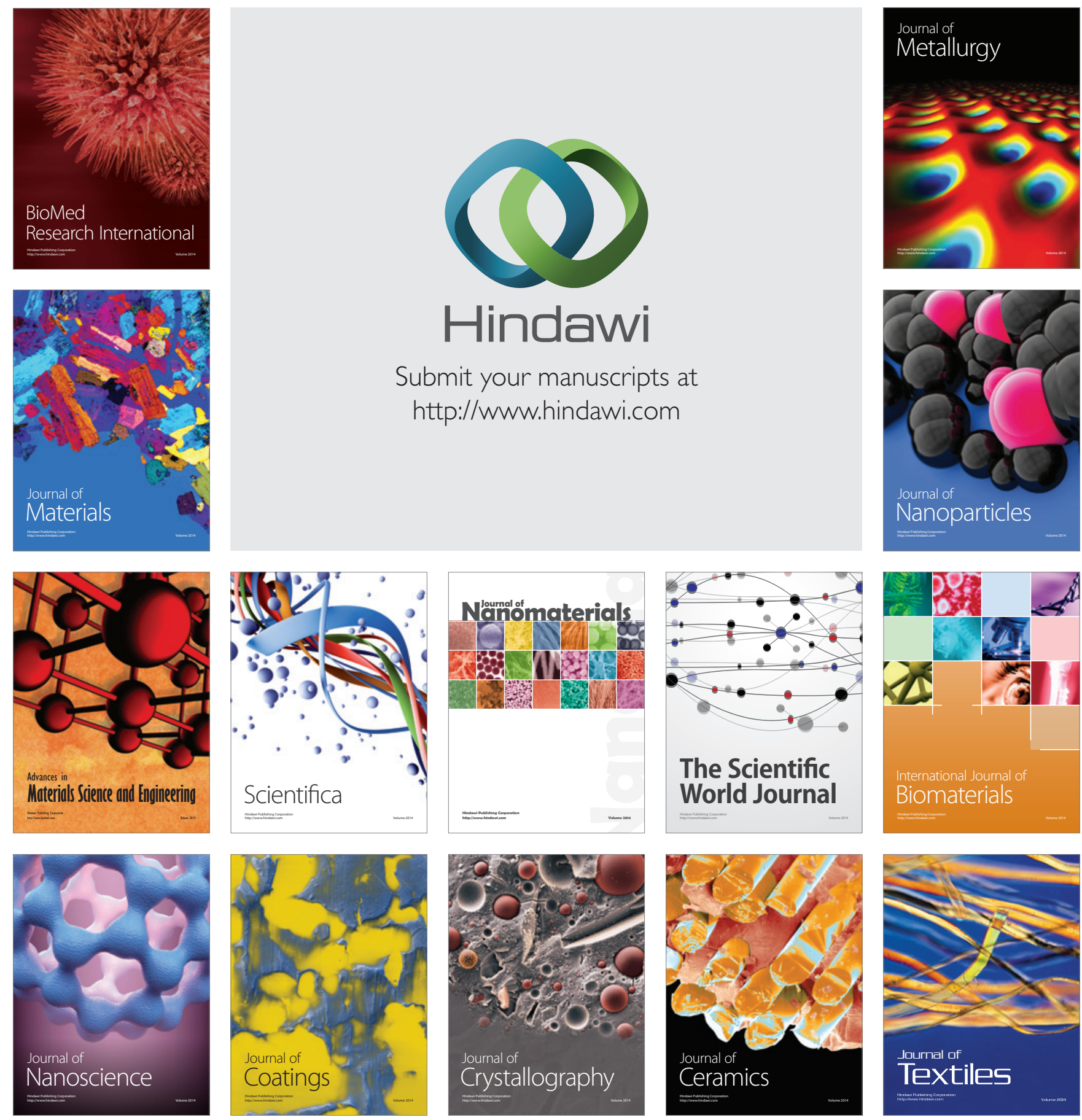